\title{
Hydro-Wind Balance in Daily Electricity Markets: A Case-study
}

\author{
Hugo Algarvio, ${ }^{1,2, \star}$ Fernando Lopes ${ }^{1}$ and João Santana ${ }^{2,3, \star}$ \\ 1 LNEG-National Research Institute, Est. Paço do Lumiar 22, Lisbon, Portugal \\ fernando.lopes@lneg.pt \\ 2 Instituto Superior Técnico, Universidade de Lisboa, Lisbon, Portugal \\ \{hugo.algarvio, jsantana\}@tecnico.ulisboa.pt \\ 3 INESC-ID, Rua Alves Redol 9, 1000-029 Lisbon, Portugal
}

\begin{abstract}
The European Union has been one of the major drivers of the development of renewable energy. In Portugal, renewable generation is subject to specific licensing requirements and benefits from a feedin-tariff. This paper pays special attention to wind and hydroelectric technologies. Typically, wind farms produce more energy during the night (off-peak periods), when the demand is lower, contributing to a reduction of the market price. Hydroelectric power plants use off-peak periods to pump water, and produce energy in the periods of a 24 hour day where the prices of electricity are higher (peak periods). This paper presents a case study aiming at analyzing the behavior of hydroelectric power producers - that is, in power systems with large renewable generation, producers typically use the periods of the day with lower energy prices for pumping, and the other periods (with higher energy prices) to produce electricity. The simulations are performed using MATREM (for MultiAgent Trading in Electricity Markets). The results confirm (and rebate) the typical behavior of hydroelectric power producers.
\end{abstract}

Keywords: Electricity markets, day-ahead markets, wind power, hydroelectric power, the MATREM system.

\section{Introduction}

The goals of the European Union (EU) include the global leadership of Europe in renewables, the integration of variable renewable energy (VRE) in electricity markets, and the increase of the general welfare of consumers. To comply with these goals, European countries have been incentivizing VRE investors, notably with feed-in-tariffs. However, the increasing levels of variable renewable energy, such as solar and wind power (WP), are raising some difficulties to energy markets (see, e.g., [1]). VRE depends on meteorological conditions, meaning that it is not dispatchable (but see [2]).

\footnotetext{
* This work was supported by "Fundação para a Ciência e Tecnologia" with references UID/CEC/50021/2013 and PD/BD/105863/2014 (H. Algarvio).
} 
The European day-ahead markets (DAMs) close at 12 noon (CET), 12-36 hours before real-time operation. Typically, the global forecast systems update the meteorological information every six hours, starting at 12 midnight (UTC). So, the forecasts for variable renewable energy use meteorological data from 17 to 41 hours before physical delivery [3]. The marginal cost of variable generation is zero, or near-zero.

The bids that VRE producers submit in the DAM are based on forecasts, which can result in substantial deviations in relation to real-time production. These deviations should be compensated with very fast responsive power plants, such as hydroelectric power plants (HPPs). Accordingly, in the periods of a 24 hour day where exist an excess of renewable production (in comparison with the demand), HPPs can use that excess for pumping water at very low prices, instead of curtailing the production of variable renewable energy. Following the pumping of water, HPPs can use that water to produce electricity during peak periods (when the prices of electricity are higher). In general, this procedure increases the efficiency of the power systems and decreases the waste of ("free-of-cost") variable renewable energy.

This paper is devoted to the study of wind power forecasts, wind power bidding, and the operation of hydroelectric power plants, notably the hydro-wind balance in day-ahead markets. Wind power is very variable and its penetration in some systems achieved such a value that it is really important to consider dispatchable power plants able to exhibit a fast response to ramps (see e.g., [3, 4]). Nuclear power plants should have (by nature) a stable operation, coal power plants have a very slow response, and fuel oil power plants have high marginal costs. Accordingly, hydroelectric power plants with reservoir and cycle combined gas turbines (CCGT) are often considered the best solution to resolve some problems associated with the variability and uncertainty of renewable energy. Normally, such power plants are marginal and their production is dependent of the hydroelectricity. Basically, in a year with high hydroelectricity, cycle combined gas turbines plants have few working hours, and in a year with low hydroelectricity, they have similar working hours in relation to hydroelectric power plants with reservoir.

The paper presents a case study involving a power system with relevant penetration of hydro and wind power (more than 50\%). It aims at analysing (and confirming) the typical behaviour of hydroelectric power plants - that is, producers typically use the periods of the day with higher variable generation and/or lower prices for pumping, and the other periods (with higher prices) to produce energy. The simulations are performed with an agent-based tool, called MATREM (for Multi-Agent Trading in Electricity Markets).

The remainder of the paper is structured as follows. Section 2 addresses the key issues of wind power forecasts and the operation of hydroelectric power plants with storage, placing emphasis on bidding strategies. Section 3 presents a brief overview of the MATREM system. Section 4 presents a case study on hydro-wind balance in a day-ahead market and discusses the simulation results. Finally, section 5 states the conclusions and outlines avenues for future work. 


\section{Energy Markets and Renewable Generation}

In the Iberian market (MIBEL), the majority of the electricity is traded in the day-ahead market, which closes at 12 noon (UTC). Producers submit bids according to their marginal costs. Energy prices are computed based on the marginal pricing theory. Following the operation of the DAM, market participants can submit bids to the intra-day market (involving six trading sessions), where players can adjust their schedules. Also, national balancing markets are used to minimize deviations between supply and demand, guaranteeing the security of the power system (see, e.g., [5]).

\subsection{Wind power plants}

In the past few years, numerous approaches to forecast wind power have been developed and detailed reviews of forecasting techniques can be found in the literature (see, e.g., $[6,7])$. The existing approaches may be classified into the following three categories: numerical weather prediction (NWP) models, statistical models, and approaches involving aspects of both models.

The NWP models are an indispensable tool for wind power producers participating in electricity markets. However, one of the main sources of errors in the wind/power forecasts, even when coupled with statistical approaches, is the data provided by such models. This drawback can be partially explained by: (i) the inadequate physics of most models, (ii) the inability of models to handle sub-grid scale phenomena, and (iii) the initial and boundary conditions (ICs).

The NWP models solve the equations that govern the status of the atmosphere using numerical methods. Therefore, ICs are necessary for the numerical calculations as well as digital maps of the terrain topography and roughness. These ICs are usually obtained from global models, such as the global forecast model system with 6 hours intervals (at 12am (0), 6am (6), 12pm (12) and $6 \mathrm{pm}$ (18) UTC), taking into account the assimilation of several different type of meteorological observations.

In this paper, we consider a K-nearest neighbor method in order to obtain the deterministic forecasts using the NWP outputs [3,8]. The importance of this technique (also known as analogous forecast) has been increasing due to: (i) its easy implementation and effectiveness [9], and (ii) the fact that it is a non-parametric approach, and as such no prior assumption needs to be taken regarding the distribution of the variables to predict.

Taking into account the current limitations associated with the periods to obtain the ICs, the actual bids to the DAM considered in this work are the forecasts themselves (as in the real-world, the point forecast of the aggregated wind farms are considered). Therefore, due to the limitations of the ICs and the operational time needed to manipulate data, the schedules resulting from the day-ahead market should be partially adjusted in the intra-day market, which in turn need to be adjusted in the balancing market (but see, e.g., [4]). 


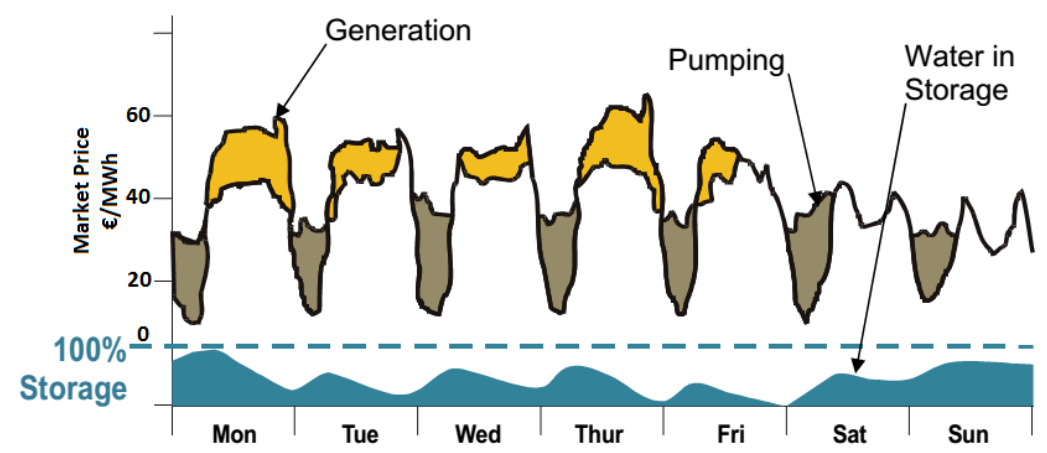

Fig. 1. Typical operation of HPPs with reservoir (adapted from [11])

\subsection{Typical operation of hydroelectric power plants with reservoir}

In power systems with a high penetration of renewables (specially VRE), HPPs with reservoir typically consider the periods of a 24 hour day with the higher shares of VRE and/or lower prices for pumping, and the other periods (with higher prices) for producing energy (see Figure 1).

HPPs with reservoir may act in the supply-side, as producers, and in the demand-side, as consumers (for pumping). Their bids are very important and should be defined as rigorously as possible. To this end, players should take into account the following: current storage, future outflow (production and other losses), future inflow (rain and pumping), and the rates of outflow and inflow of water. In this work, we consider the aggregation of all HPPs with reservoir and the bids of the resulting player are obtained by taking into account the nominal power, current storage and the social value of water.

The social value of water for electricity production can be considered the value that avoids (i.e., rules out) the more expensive power plants [10]. This value depends of the seasonality of the production (time of operation), historical data for the inflow rate (rain), and also the hydroelectricity of the year (a low hydroelectricity refers to a dry year and a high hydroelectricity refers to a humid year). Normally, in a common hydroelectricity year (with a storage capacity filled more than 50\%), the social value of water is the value that allows to rule out (of the market) the CCGT power plants. In the years with high hydroelectricity, the water value of hydropower may be lower than the values associated with coal power plants, but higher than the the common values for nuclear power plants. Otherwise, in the years with low hydroelectricity and a storage capacity filled bellow $50 \%$, the water value of hydropower is higher than the common values for CCGT power plants, but lower than the values for fuel oil power plants. So, the social value of water for electricity production may be considered a value that rule out the more expensive power plants, in such a way that does not affect the future storage capacity [11]. 
Table 1. Key features of producer agents (software agents)

\begin{tabular}{lcccc}
\hline \multicolumn{1}{c}{ Agent } & Technology & $\begin{array}{c}\text { Power } \\
(\mathrm{MW})\end{array}$ & $\begin{array}{c}\text { Marginal Price } \\
(€ / \mathrm{MWh})\end{array}$ & $\begin{array}{c}\text { Bidding Price } \\
(€ / \mathrm{MWh})\end{array}$ \\
\hline GenCo WindPower & Wind & 2000.00 & 0.00 & 0.00 \\
GenCo Thermal & Coal & 638.00 & 45.00 & 45.00 \\
GenCo HydroPower & Hydro & 2000.00 & 0.00 & 50.00 \\
GenCo CCGT 1 & Gas & 830.00 & 54.50 & 54.50 \\
GenCo CCGT 2 & Gas & 990.00 & 56.12 & 56.12 \\
GenCo CCGT 3 & Gas & 1176.00 & 57.90 & 57.90 \\
\hline
\end{tabular}

\section{The MATREM system: An Overview}

MATREM is an agent-based system composed by a power exchange and a derivatives exchange (see [12] for a detailed description of the system and [13] for its classification according to a number of dimensions related to both competitive energy markets and software agents).

In short, MATREM is able to simulate the day-ahead markets (see, e.g., [14]), the intra-day markets (based on auctions), the balancing markets (see, e.g., [2]), the futures markets, and also the negotiation of bilateral agreements (see, e.g., [15]). The pricing mechanism of the day-ahead and intra-day markets is founded on the marginal pricing theory, specifically using the system marginal pricing (typical of European markets) or the locational marginal pricing (typical of North-American markets). The balancing markets consider an asymmetric auction, also founded on the marginal pricing theory, where transmission system operators define the requirements of power systems and market participants submit bids to buy or sell energy. The futures markets consider a direct match (pay-as-bis scheme) between offers to sell and buy electricity. Bilateral agreements can be negotiated privately between two parties, namely agreements involving the details of tailored (or customized) long-term bilateral contracts. The system is also able to simulate new elements of market design, giving suggestions for the design of (future) electricity markets with high penetrations of VRE (see, e.g., [1]).

\section{The Case-Study}

This study involves a simplification of the Portuguese electric power system, by considering six generation companies (GenCos) and five retail companies (RetailCos). These eleven market players are modeled as software agents and implemented in the MATREM system. Several key features of the GenCo agents are shown in Table 1, including the generation technology, the maximum capacity and the production cost. The producer agent named "GenCo HydroPower" makes bids to sell energy (3000 MW) in the DAM at $50 € / \mathrm{MWh}$ (assumed to be the water value of hydropower). 


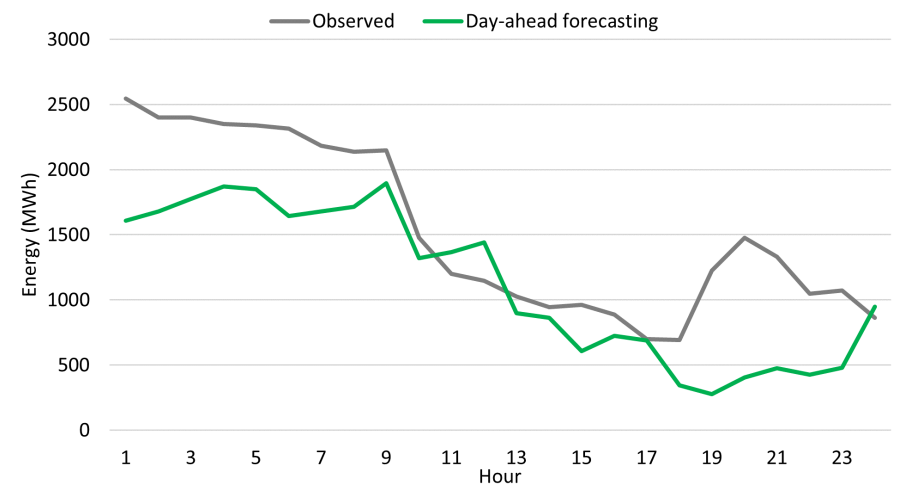

Fig. 2. GenCo WindPower agent: day-ahead forecast and real data

Figure 2 shows the hourly wind production data for the producer agent named "GenCo WindPower" in a typical day, together with the wind power forecast (the methodology employed was described in section 2.1). The bids of this agent in the day-ahead market are assumed to be equal to the forecast. The figure also presents the difference between the forecast values at 6 a.m. (17 and 41 hours prior to real time production) offered in the DAM, and the (real) observed production.

The purpose of the case study is to analyse - and confirm - the typical behaviour of HPPs. Specifically, in power systems with high penetration of VRE, HPPs with reservoir often use the periods of a 24 hour day with high VRE penetration and/or lower prices for pumping, and the other periods (with higher prices) to produce electricity. Accordingly, the producer agent "GenCo HydroPower" considers both bids to sell and offers to buy energy. In this way, the demand-side is represented by five retailers and the producer agent ("GenCo HydroPower"). Table 2 shows the minimum and maximum energy quantities and prices of the six buyers (to offer in the DAM) in a particular day of operation. As shown in the Table, the agent "GenCo HydroPower" considers offers to buy $3000 \mathrm{MW}$ at $10 € / \mathrm{MWh}$ (assumed to be the pumping value).

Table 2. Retailer agents: day-ahead offers

\begin{tabular}{lcccc}
\hline \multicolumn{1}{c}{ Agent } & \multicolumn{2}{c}{ Quantity $(\mathrm{MWh})$} & \multicolumn{2}{c}{ Price(€/MWh) } \\
& Min. & Max. & Min. & Max. \\
\hline Best Energy & 191.92 & 530.07 & 51.59 & 60.34 \\
SCO Corporation & 440.45 & 1406.46 & 55.59 & 66.01 \\
Electro Center & 91.73 & 419.64 & 56.59 & 67.01 \\
First Energy & 351.89 & 1208.52 & 47.59 & 58.00 \\
David Owen & 505.54 & 1603.97 & 37.59 & 48.00 \\
GenCo HydroPower & 3000.00 & 3000.00 & 10.00 & 10.00 \\
\hline
\end{tabular}




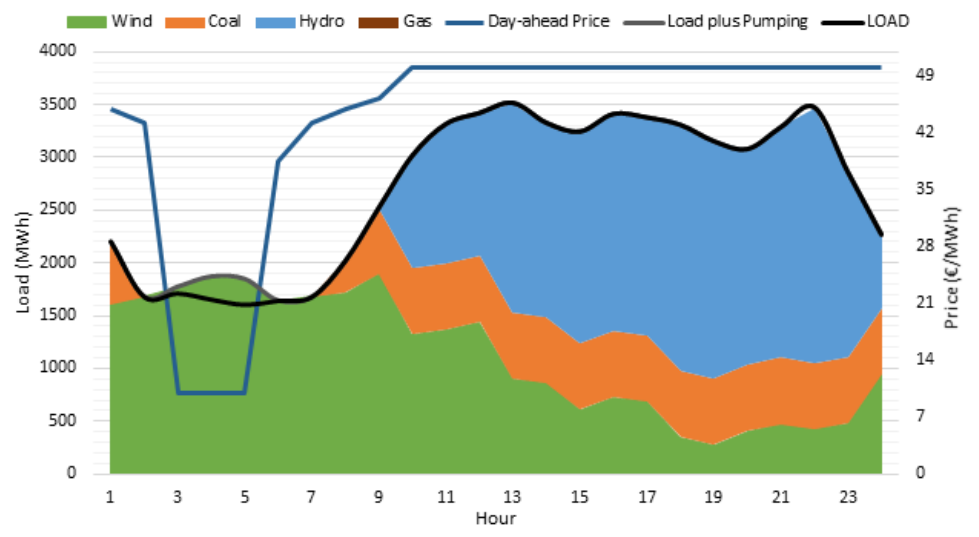

Fig. 3. Day-ahead load and prices

The results are presented in Figure 3, namely the market-clearing prices and the power commitments. Clearly, between 3 a.m. and 5 a.m., when the demand is satisfied by wind power only (green color in the figure), and the market prices are low, there is the possibility to pump (specifically, $62.73 \mathrm{MWh}$ at 3 a.m., $216.54 \mathrm{MWh}$ at 4 a.m., and $240.78 \mathrm{MWh}$ at 5 a.m.). Also, between $10 \mathrm{a} . \mathrm{m}$. and midnight, the production of hydro energy is required (blue color in the figure). This occurs because of the reduction in wind power production (apart from the increase in demand). In this period, the production of the agent "GenCo HydroPower" ranges between 693.63 MWh and 2418.44 MWh.

Figure 4 shows part of the hydro-wind balance, namely the part that takes into account the pumping of HPPs from hour 3 to 5, where WP is enough to satisfy the load. Furthermore, between hours 9 and 24, the hydroelectric production increases (because the water value is lower than the marginal price of CCGT power plants). The figure allows us to conclude that HPPs are dependent of wind power. Basically, when exists excess of wind power, HPPs consider such excess to pump at low prices, and when wind power is low, HPPs produce energy at high costs. Thus, we can assume an "informal" balance between these two technologies. This kind of "cooperation" is more important in balancing markets (during real-time operation), where HPPs can compensate the variability and uncertainty of wind generation.

\section{Conclusion}

This article has presented a case study with the aim of analysing the typical behaviour of HPPs. Several key features of agents from the supply and demandside able to make bids in spot markets were defined. Special attention was paid to wind and hydro technologies, their bids in day-ahead markets, and the hydrowind balance. The study was performed with the agent-based system MATREM. 


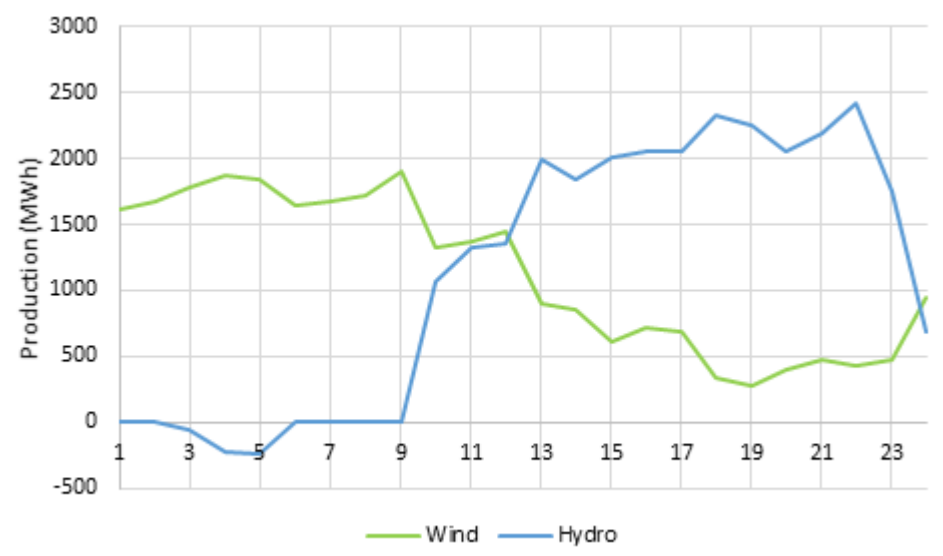

Fig. 4. Simulation results: part of hydro-wind balance

The results are consistent and confirmed the typical behaviour of HPPs in a typical market scenario. Specifically, the main results are summarized as follows:

- Between hours 3 and 5 , when the demand is satisfied by wind power (WP) with offers at $0 € / M W h$, lower than the pumping value (10€/MWh), HPPs are the marginal players and pump water at $10 € / \mathrm{MWh}$, instead of waste ("free-of-cost") wind power;

- Between hours 9 and 24, there was a significant decrease in WP production, and an increase in the demand; so wind and coal power plants were not sufficient to satisfy demand, meaning that HPPs are the marginal suppliers and their water value (the price they offer) are the marginal price of the market;

- During the other hours, wind and coal power plants are sufficient to satisfy the demand, and thus coal is the marginal technology.

To conclude, HPPs are very important to compensate the wind power variability, since in cases of excess of wind power, HPPs can pump water (the alternatives are expensive storage technologies, such as batteries). And in cases of wind power decreases, HPPs can respond fast to compensate such decreases using a "free-of-cost" resource (water), receiving at least the social value of water without producing $\mathrm{CO}_{2}$ emissions (the alternatives are fast CCGT or fuel-oil power plants, with high marginal costs and $\mathrm{CO}_{2}$ emission).

\section{References}

1. Lopes, F., Coelho, H.: Electricity Markets with Increasing Levels of Renewable Generation: Structure, Operation, Agent-based Simulation and Emerging Designs. Springer, Cham (2018) https://doi.org/10.1007/978-3-319-74263-2 
2. Algarvio H., Lopes F., Couto A., Estanqueiro A.: Participation of Wind Power Producers in Day-ahead and Balancing Markets: An Overview and a Simulationbased Study. WIREs Energy and Environment (2019) https://doi.org/10.1002/ wene. 343

3. Couto, A., Costa, P., Rodrigues, L., Lopes, V. V., Estanqueiro, A.: Impact of Weather Regimes on the Wind Power Ramp Forecast in Portugal. IEEE Trans. Sustain. Energy 6(3), pp. 934-942 (2015)

4. Skytte, K. Bobo, L.: Increasing the value of wind: From passive to active actors in multiple power markets, WIREs Energy and Environment (2018) https://doi. org/10.1002/wene.328.

5. Algarvio, H., Couto, A., Lopes, F., Santana, S., Estanqueiro, A.: Effects of Regulating the European Internal Market on the integration of Variable Renewable Energy. WIREs Energy and Environment (2019) https://doi.org/10.1002/ wene. 346

6. Giebel, G., Brownsword, R., Kariniotakis, G., Denhard, M., Draxl, C.: The StateOf-The-Art in Short-Term Prediction of Wind Power: A literature Overview. Tech. Rep., ANEMOS.plus Project, pp. 1-110 (2011)

7. Jung, J., Broadwater, R. P.: Current status and future advances for wind speed and power forecasting. Renew. Sustain. Energy Rev. 31, pp. $762-777$ (2014)

8. Zorita, E., Von Storch, H.: The analog method as a simple statistical downscaling technique: Comparison with more complicated methods. J. Clim. 12(8), pp. 24742489 (1999)

9. Taneja, S., Gupta, C., Goyal, K., Gureja, D.: An Enhanced K-Nearest Neighbor Algorithm Using Information Gain and Clustering. In: Fourth International Conference on Advanced Computing \& Communication Technologies, pp. 325-329 (2014)

10. Wolfgang, O., Haugstad, A., Mo, B., Gjelsvik, A.: Hydro reservoir handling in Norway before and after deregulation, Energy 34, pp. 1642-1651 (2009)

11. MWH: Technical Analysis of Pumped Storage and Integration with Wind Power in the Pacific Northwest. Final Report prepared for: U.S. Army Corps of Engineers Northwest Division Hydroelectric Design Center (August 2009)

12. Lopes, F.: MATREM: An Agent-based Simulation Tool for Electricity Markets. In: Electricity Markets with Increasing Levels of Renewable Generation: Structure, Operation, Agent-based Simulation and Emerging Designs, pp. 189-225, Springer, Cham (2018) https://doi.org/10.1007/978-3-319-74263-2_8

13. Lopes, F., Coelho, H.: Electricity Markets and Intelligent Agents. Part II: Agent Architectures and Capabilities. In: Electricity Markets with Increasing Levels of Renewable Generation: Structure, Operation, Agent-based Simulation and Emerging Designs, pp. 49-77, Springer, Cham (2018) https://doi.org/10.1007/ 978-3-319-74263-2_3

14. Lopes, F., Sá, J., Santana, J.: Renewable Generation, Support Policies and the Merit Order Effect: A Comprehensive Overview and the Case of Wind Power in Portugal. In: Electricity Markets with Increasing Levels of Renewable Generation: Structure, Operation, Agent-based Simulation and Emerging Designs, pp. 227-263, Springer, Cham (2018) https://doi.org/10.1007/978-3-319-74263-2_9

15. Lopes, F., Algarvio, H., Santana, J.: Agent-based Simulation of Electricity Markets: Risk Management and Contracts for Difference. In: Agent-based Modelling of Sustainable Behaviors, pp. 207-225, Springer, Cham (2017) https://doi.org/10. $1007 / 978-3-319-46331-5 \_10$ 